\title{
Outcomes of very elderly ( $\geq 80$ years) critical-ill patients in a medical intensive care unit of a tertiary hospital in Korea
}

\author{
Seung Hun Lee, Tae Won Lee, Sunmi Ju, Jung-Wan Yoo, Seung Jun Lee, Yu Ji Cho, Yi Yeong Jeong, Jong \\ Deog Lee, and Ho Cheol Kim
}

Department of Internal Medicine, Gyeongsang National University Hospital and Institute of Health Sciences, Gyeongsang National University, Jinju, Korea

Received: October 8, 2015

Revised : April 10, 2016

Accepted: April 11, 2016

Correspondence to

Ho Cheol Kim, M.D.

Department of Internal Medicine, Gyeongsang National

University School of Medicine,

15 Jinju-daero 816beon-gil, Jinju

52727 , Korea

Tel: +82-55-750-8684

Fax: +82-55-750-8618

E-mail: hockkim@gnu.ac.kr
Background/Aims: This study evaluated clinical characteristics and outcomes in very elderly ( $\geq 80$ years of age) critical-ill patients admitted to a medical intensive care unit (MICU) in a regional single tertiary hospital.

Methods: We retrospectively evaluated prospectively collected data in the MICU for the period of December 2011 to May 2014. Patients were divided into $\geq 80$ and $<80$ years of age and clinical characteristics and outcomes were compared among these patients.

Results: A total of 468 patients were evaluated and 102 patients (21.7\%) were $\geq$ 80 years of age. Overall mortality was $38.5 \%$ in the intensive care unit (ICU) and $44.7 \%$ in the hospital. There was no significant difference in ICU and in-hospital mortalities between those $\geq 80$ years and those $<8$ o years $(34.9 \%$ vs. $39.5 \%$ for ICU mortality; $40.6 \%$ vs. $45.9 \%$ for in-hospital mortality). Lengths of ICU and hospital stays were significantly longer in patients $<80$ years compared to patients $\geq 80$ years $(10.57 \pm 19.96$ days vs. $8.19 \pm 8.78$ days for ICU stay; $27.95 \pm 39.62$ days vs. 18.17 \pm 15.44 days for hospital stay). The rate of withholding intensive care in hospital stay over 48 hours was significantly higher in patients $\geq 80$ years compared to patients $<80$ years $(22.9 \%$ vs. $11.8 \%)$. In multivariate analysis, weaning failure and withdrawal or withholding of intensive care in ICU was significantly related to death in patients with age $\geq 80$.

Conclusions: Clinical outcomes were not significantly different for very elderly critical-ill patients compared to those of their younger counterparts in the MICU in this study.

Keywords: Aged; Intensive care units; Outcomes

\section{INTRODUCTION}

People aged 65 and older are the fastest growing segment in worldwide. As the older population increases, the number of elderly patients who receive critical care services is expected to increase substantially over the next 10 to 20 years. Patients will be older, often with decreased functional reserves and increased comorbidities, and older patients are more likely to be died and discharge to nursing hospital or homes [1-3].

The very old patients age 80 and older, are the most rapidly growing age group because of accelerating aging population in Korea [4]. There has been reported recently some demographic study for intensive care unit (ICU) 
in Korea [5-7]. These studies described the general characteristics and epidemiologic survey for current status of ICU in Korea. Focusing to very elderly patients in ICU was lacking [7]. There this study evaluated clinical characteristics and outcomes in very elderly ( $\geq 80$ years of age) critical-ill patients admitted to a medical intensive care unit (MICU) in a regional single tertiary hospital in Korea.

\section{METHODS}

\section{Patients}

All critical-ill patients who were admitted to the MICU at Gyeongsang National University Hospital (hospital total, 890 beds; MICU, 13 to 15 beds) between December 2011 and May 2014 were retrospectively studied. The admission was decided by attending physician according to general criteria of ICU admission [8]. There was no age limitation for admission to ICU. Before admission, consents were received from patients' family or caregiver.

The study population was divided into two groups by age: $\geq 80$ and $<8$ o years of age. Patient demographic and clinical characteristic data were prospectively collected and compared retrospectively these data between two groups. The following data were analyzed: sociodemographic data, such as age, sex, body mass index (BMI), and chronic underlying disease; the reason for admission, severity of illness, as measured by the Acute Physiology and Chronic Health Evaluation II (APACHE II) and Sequential Organ Failure Assessment (SOFA) at admission [9]; length of ICU and hospital stay; and outcome data, including survival status at ICU and hospital discharge. There was no written ICU admission policy regarding patient's age.

\section{Statistical analysis}

All data were analyzed using SPSS version 21.o (IBM Co., Armonk, NY, USA). Categorical data are presented as frequencies and percentages. For continuous variables, mean \pm standard deviation were used. Independent $t$ test (continuous variables) and chi-square test (categorical variables) were used for univariate analysis when comparing age groups and survivors and non-survivors group. All variables showing $p<0.05$ in the univariate analysis were considered for multivariate analysis, using multiple logistic regression analysis. We performed multivariate analysis to adjust for prognostic variables, including mechanical ventilation, time in ventilator, number of withhold or withdraw life-sustaining treatments, surgery, SAPS III (Simplified Acute Physiology Score III), and comorbidity.

\section{RESULTS}

A total of 481 patients were admitted to the MICU during the study period. Of these, 13 were excluded because of insufficient medical record, and total of 468 patients were evaluated. A hundred and two patients (21.7\%) were $\geq 80$ years of age. Overall mortality was $38.5 \%$ in the ICU and $44.7 \%$ in the hospital in whole patient's population. Table 1 was presented with baseline characteristics of enrolled patients.

\section{Comparison of patients aged less than 80 and over 80}

Data are presented in Table 2. Mean age was 64.1 years for the younger group ( $<80$ years) and 83.8 years for patients $\geq 80$ years. Male was more common in younger age group than in the older group (69.6\% vs. 50.9\%).

Table 1. Baseline characteristics of enrolled patients

\begin{tabular}{lc}
\hline Characteristic & Value \\
\hline No. of patients & 468 \\
Age, yr & $68.6 \pm 13.9(18-94)$ \\
Age $\geq 80$ years old & $106(22.6)$ \\
Sex, female/male & $162 / 306$ \\
BMI, kg/m ${ }^{2}$ & $21.5 \pm 3.9(12.2-39.6)$ \\
APACHE II score & $18.8 \pm 8.8(3-51)$ \\
SOFA score & $7.9 \pm 4.4(0-22)$ \\
Duration of MV, day & $9.6 \pm 17.0(0-286)$ \\
ICU LOS, day & $10.0 \pm 18.1(0-293)$ \\
Hospital LOS, day & $25.7 \pm 35.8(0-353)$ \\
ICU death & $180(38.5)$ \\
In-hospital death & $209(44.7)$ \\
\hline
\end{tabular}

Values are presented as mean $\pm \mathrm{SD}$ (range) or number (\%). BMI, body mass index; APACHE II, Acute Physiology and Chronic Health Evaluation II; SOFA, Sequential Organ Failure Assessment; MV, mechanical ventilation; ICU, intensive care unit; LOS, length of stay. 
Table 2. Comparison of baseline characteristics between age $\geq 80$ and age $<80$

\begin{tabular}{|c|c|c|c|}
\hline Characteristic & Age $\geq 80(n=106)$ & Age $<80(n=362)$ & $p$ value \\
\hline Age, yr & $83.82 \pm 3.45$ & $64.12 \pm 12.53$ & 0.000 \\
\hline Male sex & $54(50.9)$ & $252(69.6)$ & 0.000 \\
\hline Body mass index & $20.73 \pm 3.71$ & $21.45 \pm 4.00$ & 0.021 \\
\hline SOFA score & $6.80 \pm 3.98$ & $8.21 \pm 4.47$ & 0.004 \\
\hline APACHE II score & $17.61 \pm 8.30$ & $19.18 \pm 8.97$ & 0.109 \\
\hline Diabetes mellitus & $25(23.6)$ & $130(35 \cdot 9)$ & 0.018 \\
\hline Heart disease & $26(24 \cdot 5)$ & $63(17.4)$ & 0.100 \\
\hline Liver disease & $5(4 \cdot 7)$ & $58(16.0)$ & 0.003 \\
\hline Renal disease & $18(17.0)$ & $99(27 \cdot 3)$ & 0.030 \\
\hline Malignancy & $8(7 \cdot 5)$ & $51(14.1)$ & 0.074 \\
\hline Neurovascular disease & $12(11.3)$ & $45(12.4)$ & 0.759 \\
\hline Severe sepsis/septic shock & $32(30.5)$ & $130(36.4)$ & 0.262 \\
\hline ARDS & $21(19.8)$ & $52(14 \cdot 4)$ & 0.174 \\
\hline MV (invasive) & $105(99.1)$ & $345(95 \cdot 3)$ & 0.077 \\
\hline Duration of MV, day & $8.33 \pm 8.56$ & $10.00 \pm 18.78$ & 0.379 \\
\hline ICU stay, day & $8.19 \pm 8.78$ & $10.57 \pm 19.97$ & 0.079 \\
\hline Hospital stay, day & $18.17 \pm 15.45$ & $27.95 \pm 39.63$ & 0.000 \\
\hline Death in ICU & $37(34 \cdot 9)$ & $143(39 \cdot 5)$ & 0.392 \\
\hline Death in hospital & $43(40.6)$ & $166(45 \cdot 9)$ & 0.335 \\
\hline Death, $<48$ hours after ICU admission $(n=148)$ & $13 / 33(39.4)$ & $62 / 115(53 \cdot 9)$ & 0.141 \\
\hline Weaning failure & $28(26.4)$ & $87(24.0)$ & 0.616 \\
\hline Unplanned extubation & $7(6.6)$ & $23(6.4)$ & 0.926 \\
\hline Tracheostomy & $6(5 \cdot 7)$ & $44(12.2)$ & 0.322 \\
\hline Re-intubation & $8(7 \cdot 5)$ & $35(9.7)$ & 0.506 \\
\hline Renal replacement therapy & $20(18.9)$ & $93(25 \cdot 7)$ & 0.149 \\
\hline Transfusion & $29(27.4)$ & $150(41.4)$ & 0.009 \\
\hline Withdrawal or withholding of intensive care in ICU & $23(21.7)$ & $54(14 \cdot 9)$ & 0.098 \\
\hline
\end{tabular}

Values are presented as mean $\pm \mathrm{SD}$ or number (\%).

SOFA, Sequential Organ Failure Assessment; APACHE II, Acute Physiology and Chronic Health Evaluation II; ARDS, acute respiratory distress syndrome; MV, mechanical ventilation; ICU, intensive care unit.

BMI and SOFA score at admission were higher than in younger age group than in the older group $(21.5 \pm 4$ vs. $20.7 \pm 3.7$ and $8.2 \pm 8.9$ vs. $17.6 \pm 8.3$ ). As underlying disease, diabetes, liver disease, and renal disease were more common in younger age group than in the older group (35.9\% vs. $23.6 \%, 16 \%$ vs. $4.7 \%$, and $27.3 \%$ vs. $17 \%$ ). Malignant disease was also more common in younger age group than in the older group ( $14.1 \%$ vs. $7.5 \%)$. As a clinical outcome, duration of hospital stay was longer in younger age group than in the older group $(27.95 \pm 39.63$ days vs. $18.17 \pm 15.45$ days). Mortality rate in ICU and hos- pital between younger age group and the older group were not significantly different $34.9 \%$ vs. $39.5 \%$ and $40.6 \%$ vs. $45.9 \%)$. The rate of weaning failure and unplanned extubation were also not significantly different between younger age group and the older group. Transfusion was performed more commonly in younger age group than in the older group (41.4\% vs. $27.4 \%$ ). Withdrawal or withholding of intensive care in ICU stayed over 48 hours were more common in the older group than in younger age group (22.9\% vs. $11.8 \%, p=0.012)$. 


\section{Comparison between survivors and non-survivors in patients with age over 80}

Characteristics of survivors and non-survivors are summarized in Table 3. SOFA and APACHE II score indicated that non-survived group had a considerable severity of the acute illness at admission (9.11 \pm 4.35 vs. $5.57 \pm$ 3.17 and $21.59 \pm 8.34$ vs. $15.48 \pm 7.51$ ). As underling disease, renal disease and rate of severe sepsis and septic shock were more common in the older group than in younger age group. Non-survivors had significantly more renal replacement therapy and requirement of transfusion (32.4\% vs. $11.6 \%$ and $45.9 \%$ vs. $17.4 \%$ ). Non-survivors had a significantly higher degree of withhold or withdraw life-sustaining treatments (40.5\% vs. 11.6\%). In multivariate analysis, weaning failure and withdrawal or withholding of intensive care in ICU was significantly related to death with an odds ratio of 6.968 (95\% confidence interval [CI], 1.905 to $25.488 ; p=0.003$ ) and 8.141 (95\% CI,
1.937 to $34.225 ; p=0.004$ (Table 4$)$.

\section{DISCUSSION}

In this study, a substantial portion of patients admitted in the ICU were age over 80 and in these patients stayed over 48 hours, percentage of withhold or withdrawal of sustained treatment were significant higher in these patients and weaning failure and withdrawal or withholding of intensive care in ICU was significantly related to death in these patients.

In our study, over $20 \%$ of patients admitted ICU were age over 8os. A few studies for survey for evaluating population in ICU were assessed in Korea. Thirty-eight ICUs of training hospital data showed that age over 65 years compromised $53 \%$ of the adult patients of ICU and age over 85 years were $3.7 \%$ [6]. The high proportion of $\geq$

Table 3. Comparison of baseline characteristics between survived and non-survived in patient with $\geq 80$ age

\begin{tabular}{|c|c|c|c|}
\hline Characteristic & Survivor $(n=69)$ & Non-survivor $(\mathrm{n}=37)$ & $p$ value \\
\hline Age, yr & $83.88 \pm 3.47$ & $83.70 \pm 3.46$ & 0.798 \\
\hline Male sex & $33(47.8)$ & $21(56.8)$ & 0.381 \\
\hline Body mass index & $20.78 \pm 3.49$ & $20.64 \pm 4.13$ & 0.854 \\
\hline SOFA score & $5 \cdot 57 \pm 3.17$ & $9.11 \pm 4.35$ & 0.000 \\
\hline APACHE II score & $15.48 \pm 7.51$ & $21.59 \pm 8.34$ & 0.000 \\
\hline Diabetes mellitus & $15(21.7)$ & $10(27.0)$ & 0.541 \\
\hline Heart disease & $20(29.0)$ & $6(16.2)$ & 0.145 \\
\hline Liver disease & $2(2.9)$ & $3(8.1)$ & 0.228 \\
\hline Renal disease & $7(10.1)$ & $11(29.7)$ & 0.010 \\
\hline Malignancy & $4(5.8)$ & $4(10.8)$ & 0.352 \\
\hline Neurovascular disease & $6(8.7)$ & $6(16.2)$ & 0.244 \\
\hline Severe sepsis/septic shock & $13(19.1)$ & $19(51.4)$ & 0.001 \\
\hline ARDS & $9(13.0)$ & $12(32.4)$ & 0.000 \\
\hline MV (invasive) & $68(98.6)$ & $37(100)$ & 0.462 \\
\hline Weaning failure & $9(13.0)$ & $19(51.4)$ & 0.000 \\
\hline Unplanned extubation & $7(10.1)$ & 0 & 0.045 \\
\hline Tracheostomy & $4(5.8)$ & $2(5 \cdot 4)$ & 0.568 \\
\hline Re-intubation & $8(11.6)$ & 0 & 0.031 \\
\hline Renal replacement therapy & $8(11.6)$ & $12(32.4)$ & 0.009 \\
\hline Transfusion & $12(17.4)$ & $17(45 \cdot 9)$ & 0.002 \\
\hline Withdrawal or withholding of intensive care in ICU & $8(11.6)$ & $15(40.5)$ & 0.001 \\
\hline
\end{tabular}

Values are presented as mean $\pm \mathrm{SD}$ or number (\%).

SOFA, Sequential Organ Failure Assessment; APACHE II, Acute Physiology and Chronic Health Evaluation II; ARDS, acute respiratory distress syndrome; MV, mechanical ventilation; ICU, intensive care unit. 
Table 4. Multiple logistic regressions for risk of non-survivor in ICU of $\geq 80$ years old patients

\begin{tabular}{lcc}
\hline Factor & OR (95\% CI) & p value \\
\hline SOFA score & $0.936(0.756-1.158)$ & 0.541 \\
APACHE II score & $0.950(0.870-1.038)$ & 0.254 \\
Renal disease & $1.431(0.289-7.092)$ & 0.660 \\
Severe sepsis/septic shock & $2493(0.646-9.623)$ & 0.185 \\
ARDS & $1.422(0.343-5.889)$ & 0.627 \\
Weaning failure & $6.968(1.905-25.488)$ & 0.003 \\
Unplanned extubation & 0 & 0.990 \\
Re-intubation & $0.936(0.756-1.158)$ & 0.990 \\
Renal replacement therapy & $2.244(0.384-13.126)$ & 0.370 \\
Transfusion & $2.573(0.667-9.929)$ & 0.170 \\
Withdrawal or withholding of intensive care in ICU & $8.141(1.937-34.225)$ & 0.004 \\
\hline
\end{tabular}

ICU, intensive care unit; OR, odds ratio; CI, confidence interval; SOFA, Sequential Organ Failure Assessment; APACHE II, Acute Physiology and Chronic Health Evaluation II; ARDS, acute respiratory distress syndrome.

8o-year-old patients in this study was explained by the characteristic of population in the province located in hospital. In this province located in the hospital, it is characterized with high rate of aged population over 65 years, estimated $20 \%$ or over. In addition, the hospital was only one tertiary hospital in this territory of the province. So, many critical-ill patients were transfer from local regional hospital in this area to our hospital.

Age is important prognostic factor in critical-ill patients and most studies compared outcome of very elderly ICU patients showed high mortality rate was noted in $\geq 80$ aged patient $[1,10]$. However, several studies did not showed difference of mortality rate in elderly ICU patients $[7,11]$. In this study, there was no difference of ICU and in-hospital mortality between age over 80 and age less than 80 . However, organ failure assessment like SOFA as ICU admission was lower in patients with age $\geq 80$ than in patients with age $<80$. With adjusting of severity of critical illness, we assumed that the higher ICU and in-hospital morality were expected in patients with age $\geq 80$. Lower organ failure index at admission in patients with age $\geq 80$ were explained that very critical-ill patients with organ failure was not devoted to ICU treatment with usually family decision and coexistence severe underling condition or disease. High critical illness severity score and more common comorbidity in younger patients at ICU admission can be explained with same context in our study.
Less severe critical illness with $\geq 80$ age admitting to the ICU may cause shortage of ICU facility and delayed admission of more severe critical ill patients. The shortage of ICU bed was common problem in tertiary hospital in Korea. Elderly patients with less severe critical illness admitted to ICU may cause less chance of critical care in ICU with relatively younger age patients. It may increase the morbidity and mortality rate in these patients.

Although the mortality rate was not significantly different in both group, the duration of hospital stay were significantly longer in $<80$ age patients than in $\geq 80$ age patients. This can be explained by that. When the patients $\geq 80$ age were transferred to general ward with the recovery of their critical illness, their family usually request the transfer to local nursing care facility or hospital and go back to home for home care.

As we expected, high rate of withdrawal or withholding of intensive care in $\geq 80$ age patients with ICU stay $\geq 48$ hours were observed in patients $<80$ age in this study. In addition, high rate of withdrawal or withholding of intensive care in ICU was significantly associated with death in ICU. The less requirement of transfusion in $\geq$ 80 age patients were explained same context with high rate of withdrawal or withholding of intensive care in these patients.

Although American College of Chest Physician consensus statement has a recommendation for end-of-life 
care, consensus or guideline of end-of-life care has been lacked in Asian country. The report from survey including 1,465 physicians in ICU, there was quite variable attitude and practice across the country and regions [12]. According to this report, do-not-resuscitate orders implementation was associated with religions like Protestant and Catholics. In Korea, uncomfortable feeling for end-of-life care with ICU patient's family and religious background may cause less implementation of end-oflife care and DNR (do not resuscitation) order in ICU. So, guideline should be needed to assist decision making process in end-of-life care in Korea. Limitation of life sustained treatment in elderly critical-ill patients in ICU is ethical and controversial issue. In international survey for ICU physicians, most physician disagree that age should be used as a sole criteria and specific age for life sustained decision making [13].

In this study, extubation failure were independent predictor of death in patients with $\geq 80$. Extubation failure has well known to be associated with poor clinical outcomes with high mortality rate $[14,15]$. This study showed consistent finding with previous study. This study addressed the importance of extubation failure as a predictor of poor clinical outcome in especially in very elderly patients. Physician knows the more importance and deleterious effect of extubation failure in very elderly patients and be more cautious before extubation. In other studies showed that the age is an important factor that determines the rate of reintubation after unplanned extubation [16].

There was some limitation in our study. First, because of single center study, over $20 \%$ of elderly patients admitted ICU can be over estimate than other tertiary hospital because of regional population characteristics of the hospital. Second, because exact guideline of withholding or withdrawal of left support care was not established in ICU of the hospital, decision to withhold the life support was determined by family request or clinician's subjective thinking. Third, although the data was collected prospective, analysis was evaluated retrospectively. So, the outcome should be assessed prospectively for large number of elderly patients.

In conclusion, a substantial portion of patients admitted in the ICU were age over 80 and weaning failure and withdrawal or withholding of intensive care in ICU was significantly related to death in these patients. The outcome should be evaluated in the future prospective study.

\section{KEY MESSAGE}

1. Over $20 \%$ of patients admitted intensive care unit (ICU) were $\geq 80$ years of age.

2. There was no significant difference in ICU and in-hospital mortalities between those $\geq 80$ years and those $<80$ years.

3. Weaning failure and withdrawal or withholding of intensive care in ICU was significantly related to death in patients with $\geq$ age 80 .

\section{Conflict of interest}

No potential conflict of interest relevant to this article was reported.

\section{Acknowledgments}

This work was supported by Development Fund Foundation, Gyeongsang National University, 2015.

\section{REFERENCES}

1. Bagshaw SM, Webb SA, Delaney A, et al. Very old patients admitted to intensive care in Australia and New Zealand: a multi-centre cohort analysis. Crit Care 2009;13:R45.

2. Jakob SM, Rothen HU. Intensive care 1980-1995: change in patient characteristics, nursing workload and outcome. Intensive Care Med 1997;23:1165-70.

3. Rellos K, Falagas ME, Vardakas KZ, Sermaides G, Michalopoulos A. Outcome of critically ill oldest-old patients (aged 90 and older) admitted to the intensive care unit. J Am Geriatr Soc 2006;54:110-114.

4. Statistics Korea. Population census: complete enumeration results of the 2015 population and housing census [Internet]. Daejeon (KR): Statistics Korea, c1996 [cited 2017 May 17]. Available from: http://kostat.go.kr/portal/eng.

5. Jeong BH, Suh GY, An JY, et al. Clinical demographics and outcomes in mechanically ventilated patients in Korean intensive care units. J Korean Med Sci 2014;29:864870.

6. Kwak SH, Jeong CW, Lee SH, Lee HJ, Koh Y. Current status of intensive care units registered as critical care sub- 
specialty training hospitals in Korea. J Korean Med Sci 2014;29:431-437.

7. Sim YS, Jung H, Shin TR, Kim DG, Park SM. Mortality and outcomes in very elderly patients 90 years of age or older admitted to the ICU. Respir Care 2015;60:347-355.

8. Smith G, Nielsen M. ABC of intensive care: criteria for admission. BMJ 1999;318:1544-1547.

9. Moreno R, Morais P. Outcome prediction in intensive care: results of a prospective, multicentre, Portuguese study. Intensive Care Med 1997;23:177-186.

10. Fuchs L, Chronaki CE, Park S, et al. ICU admission characteristics and mortality rates among elderly and very elderly patients. Intensive Care Med 2012;38:1654-1661.

11. Somme D, Maillet JM, Gisselbrecht M, Novara A, Ract C, Fagon JY. Critically ill old and the oldest-old patients in intensive care: short- and long-term outcomes. Intensive Care Med 2003;29:2137-2143.
12. Phua J, Joynt GM, Nishimura M, et al. Withholding and withdrawal of life-sustaining treatments in intensive care units in Asia. JAMA Intern Med 2015;175:363-371.

13. Guidet B, Hodgson E, Feldman C, et al. The Durban World Congress Ethics Round Table Conference Report. II. Withholding or withdrawing of treatment in elderly patients admitted to the intensive care unit. J Crit Care 2014;29:896-901.

14. Epstein SK, Ciubotaru RL, Wong JB. Effect of failed extubation on the outcome of mechanical ventilation. Chest 1997;112:186-192.

15. Rothaar RC, Epstein SK. Extubation failure: magnitude of the problem, impact on outcomes, and prevention. Curr Opin Crit Care 2003;9:59-66.

16. Chen CM, Chan KS, Fong Y, et al. Age is an important predictor of failed unplanned extubation. Int $\mathrm{J}$ Gerontol 2010;4:120-129. 